\title{
Environmental Information in Modern Fiction and Ecocriticism
}

\author{
J. Zhang ${ }^{1 *}$, L. R. Liu ${ }^{2}$, X. C. Shi ${ }^{1}$, H. Wang ${ }^{3}$, and G. Huang ${ }^{4}$ \\ ${ }^{1}$ Department of Foreign Languages, China Women's University, Beijing 100101, China \\ ${ }^{2}$ Institute for Energy, Environment and Sustainable Communities, University of Regina, Regina, SK S4S 0A2, Canada \\ ${ }^{3}$ Department of Water Resources, China Institute of Water Resources and Hydropower Research, Beijing, 100044, China \\ ${ }^{4}$ Institute for Energy, Environment and Sustainability Research, UR-BNU, 3737 Wascana Parkway, Regina, SK S4S 0A2, Canada
}

Received 12 January 2016; revised 24 November 2016; accepted 5 December 2016; published online 28 September 2017

\begin{abstract}
Environmental writing and ecocritical inquiry have been practiced more vigorously in recent years than before, with increasing sophistication and substantial progress. In this study, the discourses of environment in modern fiction are examined from an ecocritical perspective. The literary representations of environment in modern fiction reveal new insights into environmental issues and provide new perspectives and viable documentary information for the scientific study of the environment. Trying to conceptualize some of the environmental phenomena, this study concludes that zoomorphism and anti-anthropocentrism can well balance ecocentric concerns, reflecting and enhancing the close ties and interdependence between human society and the natural world. Environmental apocalypticism is another notable concept conveyed in modern fiction, indicating great crises of the worsening environment. More importantly, environmental apocalypticism serves as an alarming reminder that the remarkable complexity of problematic environmental issues humans encounter are both urgent and devastating. With analyses of literature's engagement with the natural environment, the interdisciplinary vision highlights the interconnections between man and nature, expands research space for both disciplines and provides more efficient means of solving the environmental problems.
\end{abstract}

Keywords: environmental information, ecocriticism, zoomorphism, anti-anthropocentrism, environmental apocalypticism, Penelope Fitzgerald

\section{Introduction}

Our living environment and the quality of life are being threatened by the ecological changes due to greenhouse effect and the side-effects of industrialization. It is the irrevocable duty of literary study to exert some influence on the implementation of policies for sustainability and balanced ecological circle. The call for a union between the scientific and literary communities is urgent. Rachel Carson's Silent Spring is a good example of a combined work of novelistic skills and scientific argument. Joseph W. Meeker (Meeker, 1997) strongly argues in The Comedy of Survival for the inseparability of literature from nature, saying "If the creation of literature is an important characteristic of the human species, it should be examined carefully and honestly to discover its influence upon human behavior and the natural environment to determine what role, if any, it plays in the welfare and survival of mankind and what insight it offers into human relationships with other species and with the world around us." Ecocriticism, as a means of literary criti-

${ }^{*}$ Corresponding author. Tel.: +86 10 84659135; fax: +86 1084659135 . E-mail address: zhangju@cwu.edu.cn (J. Zhang).

ISSN: $1726-2135$ print/1684-8799 online

(C) 2017 ISEIS All rights reserved. doi:10.3808/jei.201700374 cism, answers the call timely with the "fundamental premise that human culture is connected to the physical world, affecting it and affected by it" (Glotfelty, 1996). Ecocriticism takes the interconnections between nature and culture as its subject. The combination of ecological thinking and criticism on literary works distinct from other methodology of literary criticism in that this study rouses and stresses the equality of natural and social worlds, convincingly displays and encourages the need for the conservation of nature.

Modern literary works contain plenty of eco-environmental information and the exploration of such information is very important since analyzing and interpreting the information under certain specific historical backgrounds provide new angles from which we see how social science presents and represents the environmental issues and how writers and readers of differrent times are reflecting on environment-related problems. Both the works themselves and the research on the works are irreplaceable by conventional scientific research works.

The significance of the above-mentioned two aspects has been recognized and there are already some related researches. Before the 1960s, the natural environment usually serves as an insignificant part of "setting" in literary writing and criticism. Aldous Huxley suggests in Literature and Science that if the proper study of mankind is Man, then the next most proper study is Nature, and the relationships between the two (Huxley, 
1963). The concerns of ecology are matters of great significance. Since then "environment" becomes a keyword which many influential literary and critical works explore. From the 1990s on ecocritical study has witnessed a blooming development. Now, environmental study is a legitimate field of inquiry for literary scholarship, playing a key role in a broader conception of the study of literature and the environment.

A simple fact that "Nature" is interdisciplinary convincingly calls for an interdisciplinary study between literature and the environment. Being a credible area of study nowadays, ecocriticism, a term of interdisciplinarity, is defined by Cheryll Glotfelty, the first Professor of Literature and the Environment in the United States of America, as "the study of the relationship between literature and the physical environment" (Glotfe1ty, 1996). It tries to bridge the gulf between environment study and the study of literature. It encourages and enhances the sense of interrelationships to include nonhuman as well as human contexts. "Ecological thinking about literature requires us to take the nonhuman world as seriously as previous modes of criticism have taken the realm of society and culture" (Love, 1999).

Primary and influential practitioners of ecocriticism are Joseph W. Meeker, Glen A. Love, Lawerence Buell, Jonathan Bate, Greg Garrard, the Canadian scholar Kevin Hutchings, Ursula K. Heise, Dana Philips and Stephanie LeMenager, to name but a few. Widely-acknowledged special issues have been dedicated to the interdisciplinary study of literary and environmenttal concerns. Two of the earliest are the 1991 MLA special session organized by Harold Fromm, themed "Ecocriticism: The Greening of Literary Studies" and the 1992 American Literature Association conference chaired by Glen Love on "American Nature Writing: New Contexts, New Approaches". The third is the summer issue of 1999 by quarterly New Literary History: A Journal of Theory and Interpretation, themed "ecocriticism"; another is the Fall issue of 2005 by Interdisciplinary Literary Studies: A Journal of Criticism and Theory, themed "New Connections in Ecocriticism"; the fifth is the 2011 issue of Pacific Coast Philology, themed "Literature, Culture and the Environment"; and the sixth is 2013 issue of Comparative Literature Studies, themed "Sustaining Ecocriticism: Comparative Perspectives." These academic focuses demonstrate that ecocriticism is flourishing as a widely accepted field of interdisciplinary study, transforming from an emergent and peripheral field to a highly recognized research area. The interdisciplinary approach has proved to be successful and fruitful by environmenttalists and ecocritics who have established a trend and laid a firm foundation for ecocriticism through influential monographs (most of which are included in the "References"). The Association for the Study of Literature and Environment (ASLE) was founded in 1992 .

Lawrence Buell, one of the most influential ecocritics asserts that ecocritical practice has already undergone two waves of movements, with the first wave prevailing through the 1990s and privileging rural and wild spaces over urban ones and the second wave more inclusive, regarding metropolitan landscape and the built environment as equally fruitful ground for ecocritical work (Buell, 2011).

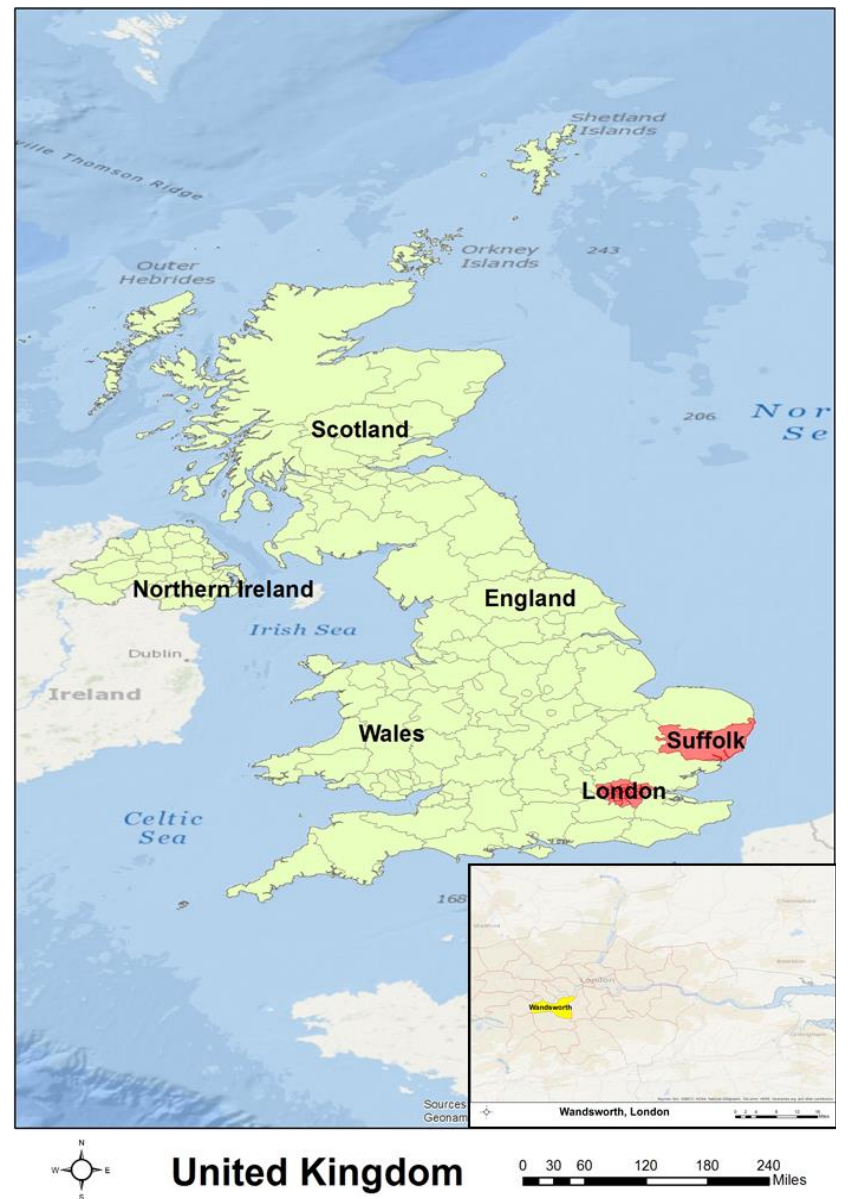

Figure 1. Geographic background.

The environmental descriptions dominate aspects of some contemporary fiction, as the setting of the stories as well as bearing significant thematic meaning. Among the contemporary literary works, Penelope Fitzgerald's fiction deserves special attention for its unique environmental writing. Being awarded two lifetime-achievement prizes, the Heywood Hill Literary Prize (1996) and the Golden PEN Award (1999), Penelope Fitzgerald is ranked $23^{\text {rd }}$ among the 50 most distinguished postwar novelists in England by The Times in 2008. Fitzgerald writes most of her works in the 1980s, focusing more on the urban landscape, which brings much space to both natural and social dimensions of environmental study and critical practice. However, her works have not been studied extensively. Few critics have given the requisite ecocritical attention to her writing of the industrial transformation of the city environment, which, most largely focuses on the urban environment instead of the uninhabited natural world as some other writers do. The real life of Penelope Fitzgerald in London, is inextricably connected with the then heavily-polluted Thames River, that of the fragile, sensitive relationship between city dwellers and the surroundings. Although there are previous discussions and special sessions on the exploration of literature and environment, no exploration of eco-environmental information within Pene- 
lope Fitzgerald's works has been undertaken. At the same time, little effort has been made in exploring eco-environmental information under the corresponding historical background in order to compensate and support the related scientific research.

Therefore, the objective of this study is to explore the significant implications of the environment discourses as well as of the people and animals who inhabit the environment within Penelope Fitzgerlad's works. Though environmental descripttion does not dominate Fitzgerald's fiction, it provokes numerous ecological discussions and provides sufficient and convincing thoughts that can be conceptualized. The conceptualization will be based on a detailed discussion applying ecocriticism as a foundation for analysis. Three issues will be addressed, including (i) how humans reflect ecological relationships with nature through zoomorphism, (ii) how anti-anthoropcentrism is expressed in Penelope Fitzgerald's works, and (iii) how environmental apocalypticism is hinted in some modern literary works and the relationship between this vision and risk management. By conceptualizing the eco-environmental implications this study reiterates the idea that nature and human survivals are interdependent and that literary works can function as invaluable documentaries that records the status-quo of the environment and people's changing attitude and consciousness towards the protection of the environment. This study will provide another angle from which scientific studies can benefit, contributing more effectively to the environment amelioration from a reinvention of vision and values.

\section{Background Information and Environmental Dimensions in Penelope Fitzgerald's Fiction}

Penelope Fitzgerald's most well-known and commented works are Offshore and The Bookshop. Set in London in the 1960s, Offshore is semi-autobiographical, as shown in Figure 1. The protagonist Nenna James' life on boat on the Thames in Battersea is based on Fitzgerald's own two-year barge life in that area. Being left behind with two daughters when the husband Edward James accepts a job overseas, Nenna manages to find a dwelling place in a houseboat (Grace) on the Thames. There she and her two daughters are in the liminality of belonging neither to the land nor the sea. To make the situation worse, Nenna has no job, little income and an absentee husband who refuses to join them after he comes back to London from Panama. Nenna and her daughters are beside a polluted river and in poor sanitary conditions, poor lighting and heating systems. They go through most of the hardships of those who are caught in between. The Booker short-listed The Bookshop centers around another unfortunate middle-aged woman, Florence Green, who makes up her mind to run a bookshop in the small coastal town of Hardborough, Suffolk. Florence has some struggles but she finally succeeds in opening the bookshop and keeps it for a year, yet the influential and ambitious Ms. Garmart tries all her means to turn the location of the bookshop, the Old House into an arts center. In the end, Ms. Garmart wins the invisible war and Florence is evicted. If one thinks that the two well-received works only excel in narrating the fate of wretched women, it will be somehow narrow-minded. Apart from revealing the social environment of the 1960s England, the two works depict in detail the respective natural environment, whose significance shall not be overlooked.

Penelope Fitzgerald has convincingly manifested an environmental consciousness in her writing. Few readers will fail to notice the deplorable condition of the Thames in the 1960 s from her Booker winner Offshore:

(a) The whole morning's mail soaked away in the great river's load of rubbish (8).

(b) 200 yards upriver and close to the rubbish disposal wharfs and the brewery, there was a great gulf fixed.... rat-ridden and neglected, it was a wharf still (19).

(c) Round about Grace herself, the great river deposited little but mounds of plastic containers (75).

(d) There, even the handlebars of a sunken bicycle can be viewed (78).

These descriptions of the Thames and its banks, dotted with a variety of refuse, seemingly objective and factual, imply unmistakably how human act, in the era of modernization and consumerist culture, has polluted the environment. Exploring the ecological implications of this piece of writing, we find a sophisticated concern about the metropolitan environment. The excerpt above reveals how issues such as waste disposal are worsening and influencing people's lives. The following example reveals, from another perspective, how post-industrialization have led to the environmental crisis.

(e) By now the flood was making fast. The mist had cleared, and to the northeast the Lots Road Power Station had discharged from its four majestic chimneys long plumes of white pearly smoke which slowly drooped and turned to dun. The lights dazzled, but on the broad face of the water there were innumerable V-shaped eddies, showing the exact position of whatever the river had not been able to hide (24).

In this part of narration, the vision of the metropolitan environment is expanded from the river itself to the air and the surroundings. What is extrusive is the Lots Road Power Station, its four majestic chimneys and the smoke! Meaning "impressive because of size or beauty", "majestic" is a positive word, indicating one's approval or admiration, but here it is used ironically. The narrator's disapproval is in proportion to the size of the chimneys and the heavy pollution they bring to the air. The color of the smoke changes from "white" to "dun", which reveals that the seemingly harmless smoke contains the substance that has been proved dangerous to man's and other living species' respiratory system.

\section{Zoomorphism and Sustainability}

Offshore and The Bookshop not only incorporate environmental concern with the narration of the story but also convey ecocritical viewpoint from an enlightening perspective. In the very opening paragraph of The Bookshop, zoomorphism is represented in a tactful way:

(f) ... a heron flying across the estuary and trying, while it was on the wing, to swallow an eel which it had caught. The eel, in turn, 
was struggling to escape from the gullet of the heron and appeared a quarter, a half, or occasionally three-quarters of the way out. The indecision expressed by both creatures was pitiable. They had taken on too much (1).

This scene has double significance. On one hand, it functions to emphasize Florence Green's dilemma in that she is like the creatures who are engaged in a life struggle. To open or not to open a bookshop in East Suffolk is an important yet hard decision that she has to wisely make. Unlike the physical fight of the two animals, what she experiences is a psychological hesitation and assessment of her situation. The heron is trying to swallow its catch, and the eel is trying to escape being swallowed. "The opening perfectly sets up the novel's story of struggle, worry and failure" (Lee, 2013). On the other hand, this scene also creates the atmosphere for a linear narrative, a story of "survival of the fittest". If the heron and the eel in the animal world "had taken on too much", they symbolize counterparts in the human world, the exterminator and the exterminatee. This metaphoric situation immediately brings forth two sides in a critical situation of life and death. Florence Green's indecisiveness is justified in this difficulty. The tension is strong. Chances of survival for the eel seem slight, which, to a large extent, presages Green's failure after all her painstaking efforts since the human world is far more complicated than that of animals. In East Suffolk in The Bookshop, coastal erosion has buried some local churches. "Survival in East Suffolk requires a sense of humor as well as toughness to withstand such a hard, fighting environment" (Wolfe, 2004). The harsh natural environment in The Bookshop corresponds to the cold and oppressive social environment. The disfavored has little opportunity to seek solace in such natural and social environments. This thematic idea is achieved and understood through zoomorphism of turning abstract indecision in Florence Green's mind into a concrete struggle between two animals. From the above analyses, it is safe to summarize that zoomorphism is the action or tendency of representing human behaviour or thoughts in terms of the behaviour of animals. Lawrence Buell points out in "Ecocriticism: Some Emerging Trends" that "Ecocriticism, for its part, has from its inception shown keen interest in the (re)conception of humans as animals ..." (Buell, 2011). Another equally convincing example of zoomorphism comes from one of Penelope Fitzgerald's short stories, “The Red-Haired Girl", in which three drowned men are mercilessly compared to fish in a market. "Once they brought in three drowned bodies, two men and a boy, a whole boat's crew, and laid them out on the tables in the fish market, and you could see blood and water running out of their mouths ..." (Fitzgerald, 2001). Un- der the calm and understated narration is the cruelest reminder that humans, after all, are a part of Nature, not superior to any other species.

Opposite to zoomorphism, which is the metaphorical treatment of humans as animals or other creatures, anthropomorphism is the metaphorical treatment of non-humans as humans. Nature's therapeutic value for men's physical and mental health is the representation of anthropomorphism. Very few people would fail to acknowledge romanticists' love of nature for inspiration and consoling power. The concept of "nature" as
"Mother Nature" is widely accepted. Simmons and Scigaj justifiably comment that Buell has the talent for making us realize that in most environmental texts the landscape is an active ethical element in thematic development (Simmons and Scigaj, 1996). This point is supported by the above analyses and discussions. This tells that as long as the environment is cast upon by human eyes, it revives more than it naturally represents. And when human thoughts or actions are reflected on in the behaviors of animals, they actually obtain a more objective standing point and more often than not, the view instantly becomes panoramic instead of being one-sided. If environmental technologies are innovated in this way, then sustainability can be more easily approached. Also, the negative impact of human behavior will be reduced if we always have the sense of how animal world operates in tackling certain difficulties (Huang and Loucks, 2000; Li et al., 2009; Nie et al., 2016; Zeng et al., 2016). The animal world has been voluntarily and constantly practiceing the four Rs: reduce, reuse, recycle and rehabilitate (Edwards, 2005). It is not risky to say that on the premise of zoomorphism develops biomimetics, the study on the imitation of elements, models and systems of nature for the purpose of handling complicated human problems. The above-mentioned literary works and the analysis of its examples direct to a route through which some environmental problems will be shed upon by new light if some of the issues are pondered from the perspective of the animal world.

\section{Environmental Apocalypticism and Risk Management}

Environmental apocalypticism directs to the ultimate perish that covers the entire ecosphere. This chapter hopes to accomplish the role of literary criticism to reinstate its "lost social role" by addressing the highest degree of threat posed by the worsening environment. We have long been embracing and celebrating works that eulogize men's power. Combating and conquering the natural world is a recognizable and noticeable characteristic in Daniel Defoe's Robinson Crusoe and Jack London's works. Nonetheless, since the twentieth century, writers turn to begin to admit the failures of certain human atempts. We come to realize the necessity of reconciling with the living environment and the necessity of sustainability.

Environmental apocalypticism is actually a warning of ecocatastrophe. Rousing widespread public worries, environmental apocalypticism is assumed to induce fatalism, referring to the ecological blight on human's future environment. To put aside the 2004 devastating tsunami in Southeast Asia and the 2005 Katrina in New Orleans, the threatening power of the Thames River in the 1960s is calmly stated in Fitzgerald's Offshore:

(g) ... one could die within sight of the Embankment (31).

(h) The whole dingy was jammed and sucked in under the stem, then rolled over, held fast by her steel mast which would not snap. The men were pitched overboard and they too were swallowed up beneath the heavy iron bottoms of the lighters (33).

It seems that these men's carelessness results in the accident but beneath that is the ignorance of the crew who took the 
flows and tides of the river for granted, which eventually leads to the tragedy. Had they been more cautious, they would not have lost their lives where land is already within reach. In Fitzgerald's works, the natural world attains a devouring power, revealing the tension between individual selfinterest and the needs of nature, reminding us that the non-human world is far beyond our control because we, more often than not, are incapable of predicting with accuracy the effects of our actions upon nature. The future of human beings is doomed if we do not stop being ignorant of nature's power and principles.

Offshore presents another example of man's ignorance and nature's damaging power in the ending part where a storm on the River Thames takes away two men's lives. Claiming that "the apocalyptic flood of the ending doesn't hold everything together", Frank Kermode hints that Penelope Fitzgerald fails to provide the story with closure, which is usually required by conventional plot structures, either in the forms of solution or a happy/unhappy ending (Kermode, 1979). However, viewing from another perspective, this ending corresponds to the environmental crisis as reflected in this work, highlighting the geographical and temporal scale, complexity and uncertainty of environment crisis instead of simply warning the readers of the urgency of environmental protection. It also dramatizes the hopelessness of humans before nature and is vivid in the foregrounding of environmental unpredictability, one of whose features is degeneracy as shown in the following example:

(i) Stripey was in a perpetual process of readjustment, not only to tides and seasons, but to the rats she encountered on the wharf. Up to a certain size, that is to say the size attained by the rats at a few weeks old, she caught and ate them, and, with a sure instinct for authority, brought in their tails to lay them at the feet of Martha. Any rats in excess of this size chased Stripey (29).

This seemingly funny scene in Offshore may be overlooked easily, but giving it a second thought we can see that the image of the terrified cat intimidated by rats who are much larger in size than it convincingly speaks of environmental degradation, where even the food chain has been reversed. The notion of imminent ecocatastrophe is clearly conveyed. There are reports on transformation and deviation of certain species due to environment change and deterioration and the above is the factual description of how certain species are reversing the traditional roles.

Environmental apocalypticism is put forward further in the red-haired girl's retrospective fear.

(j) Once they brought in three drowned bodies, two men and a boy, a whole boat's crew, and laid them out on the tables in the fish market, and you could see blood and water running out of their mouths (47).

Humans' powerlessness is degraded into desperation. A whole boat's crew, young and old, had the doomed fate and was now brought back like dead fish. The message conveyed here is that human beings, at best, are also a part of nature, with little difference from other creatures in the natural environment. The implicit chain action is alarming: men net fish, while nature can net men. This is a presentation of a dystopian future for men if not harmonized with the environment. As if inspired by the tragic accident, the girl continued philosophically:

(k) You can spend your whole life here, wash, pray, do your work, and all the time you might just as well not have been born (47).

Annihilation permeates in the girl's pessimistic yet prophesying futuristic scene of humankind: if the end of the earth came, we might just as well not have been born. Another subtle yet equally significant detailed illustration of hinted apocalypticism is at the beginning of The Bookshop, where the southeast Hardborough town is briefly sketched and one fact is understated but yet still quite alarming and thought-provoking. The fact about that town is that around every 50 years it loses a way of communication with the outer world. While humans are striving to explore the outer space, the connections that we have formerly and should have firmly built are cut off. This isolating town here somehow symbolizes our planet's long-term bleak prospect.

Closely related to the concept of environmental apocalypticism is anthropocentrism. If Man's vision is always humancentered, then the doomed future is soon to come. Herman Melville's Moby Dick impresses readers with explorations of cetology and the natural sciences, foiling Ahabian anthropocentrism and foreshadowing Ahab's ultimate failure of his revenge on nature. Nowadays problems of pollution and global climate change threaten loss of plant and animal species, which justifies writers and critics' worries. In White Noise, the 1985 National Book Award Winner, Jack Gladney and his family are trapped in the poisonous fallout from a chemical spill. Eventually Jack flees the "airborne toxic event" as understated in the officialese. Individuals can somehow figure out a way to escape from poisoned or dangerous areas but human beings as a whole would have difficulty fleeing from the planet if environmental catastrophe happens.

Environmental apocalypticism results from pollution, deforestation, overpopulation, global climate change and mass extinction of species, which are also the major concerns in environmental risk management (Huang, 1998; Li et al., 2008; Khan and Valeo, 2016; Martín-Fernández et al., 2016; Woo et al., 2016). According to ISO, risk management is the identification, assessment, and prioritization or risks, followed by coordinated and economical application of resources to minimize, monitor, and control the probability and impact of unfortunate events (Huang et al., 2006; Hubbard et al., 2009; An et al., 2016; Fan et al., 2016). In the above examples, literary works are reminding us of the limits of the eco-system and pointing to this great danger. This is a special kind of risk identification that helps readers to know various environmental risks. In addition, literature speaks loudly of the significance and urgency of the sustainability of the eco-system through the lively description of disasters. Soon we will be facing the question of whether we and the next (next-next) generation would survive or inhabit the earth and maintain a decent life. To understand the consequences of environmental disasters is very important in assessing the risk. The above-mentioned literature works are instrumental in building people's cognitions of environmenttal risk, which will further support the risk management. 


\section{Anti-anthropocentrism and Eco-Environmental Optimization}

Anti-anthropocentrism concerns the environmental-ethics and is linked to human relations with animals and how human represents animals. The cultural root of man's alienation from nature and the essence of ecological crisis are attributed to the implemented conception of anthropocentrism, explicitly indicating human dominance of the nonhuman world. Anti-anthropocentrism debunks anthropocentric view and holds an egalitarian position of both culture and nature, correcting the conception of human superiority over nature.

Penelope Fitzgerald's representation of animals in a mancentered society is appalling. In The Early Beginning of Spring, the bear-cub pet is first made drunk and then killed in an arson attack (Fitzgerald, 1998). On the surface level, a bear-cub is a vulnerable target of kids' practical jokes; while on the deep level, it is a representation of human's mistreatment of animals and our arbitrary power against the species of the natural world. Adults are absent when the cub is made drunk, but it is an adult who sets the cub on fire to extinguish its "madness" after getting drunk. Bur children are not purely innocent either. In William Golding's Lord of the Flies, a group of children survive the harshness of the island, bringing great harm both literally and metaphorically to their surroundings. Children's cruelty and brutality is objectively described in this Nobel Prize winning work.

A further good example of anti-anthropocentrism is found in Fitzgerald's Offshore:

(l) If the tide was low, the two of them watched the gleams on the foreshore, at half time they heard the water chuckling, waiting to lift the boats, at flood tide they saw the river as a powerful god, bearded with the white foam of detergents, calling home the twentyseven lost rivers of London, sighing as the night declined (52).

As a two-year dweller on the River Thames, Penelope Fitzgerald fully recognizes the power of and the interconnectedness between the Thames and its branches and the Thames and its dependent human beings. "The white foam of detergents" tactfully and clearly reveals the man-made heavy burden and pollution to the river. Here, the crude way of the 1960s waste disposal is repeatedly reproved.

Contrary to most feminized natural objects, the river here is man-like ("bearded") and is as powerful as a god. The superiority of the river to human beings is hinted. This masculinised image is rich in its connotations. Most writers have the tendency to feminize nature and they hold the view that the hurt on nature by human beings can be effectively cured because of nature's woman-like nurturing and self-repair capability. The river's healing power is later realized when Nenna was rejected and deeply hurt by her husband. Rushing out of her husband's place in a rage and regret, she left her purse behind, lost one of her shoes and her way, but she soon realized that "once she had got to the river she would be on the way home." She did. The hurt from the man was effectively healed by the river. River stands for "home", comforting and consoling, like a mother's hug. Penelope Fitzgerald's androgynous attitude towards the
River Thames expresses an inclusive and comprehensive way of treating nature.

Special attention should be drawn to while analyzing the quoted part because the perceptions of the River Thames here is from the two girls'. While most of the adult dwellers at the river are thinking of moving to the land in one way or another and most of them do in the end, the two girls are the ones that are sincerely at ease with the river and enjoy the offshore life and thus they can make the best of its tides. It is from the two girls' innocent eyes that the Thames River seems angry of being polluted and is trying to get rid of the white foam of detergents. "Calling home the twenty-seven lost rivers of London" hints the interconnectedness and the giant power of the river system and ecology, foreshadowing the harm at the end of the novel. The figure of speech here also contains Penelope Fitzgerald's androgynous mentality for breaching the gap of instinctively comparing nature to something feminine. Injustice against women and the environment, the oppression and domination of nature is diluted and Fitzgerald is considering the issue from a higher level. In some writers' works, nature's power is supposed to be either overcome or exploited in accordance with the view of most of the scientists so that human beings can boast a secure living environment. In the above-quoted description by Fitzgerald, the Thames River is powerful, sacred and fatherlike with a sense of security.

What good will man be entitled to if man harmonizes with environment? Before answering this question, it is important to relinquish the self-centeredness in the question itself. Environmental study used to be man-centered. It is a fact that both science and social science seldom truly consider nature as an equal being. With human beings in the center, the rest of the animated and inanimate in the universe constitute "environment" or "surroundings" around. But actually since Saussure, it has been convincingly argued that the center is necessarily relational and that the identity and status of the center is not permanent or always stable. The dichotomy between the center and the periphery is changeable and reversible. Sometimes the center can even be overthrown. Like in a social community where one centered sovereign can be overthrown by a peripheral force and form new center, the natural sphere can also form a new center.

Aligned with this philosophy is the argument on the interdisciplinary studies of the key teminologies "ecocriticism" and "environmentalism". The focus of the argument is on the prefixes "eco-" and "environ-". Cheryll Glotfelty's preference of "eco-" to "environ-" is illustrated as follows: "in its connotetions, enviro- is anthropocentric and dualistic, implying that we humans are at the center, surrounded by everything that is not us, the environment. Eco-, in contrast, implies interdependent communities, integrated systems, and strong connections among constituent parts" (Glotfelty, 1996). Robert Wess is on the side of Glotfelty's and he reminds that if humans see themselves as surrounded by an environment that is "apart from" them, then they obviously fail to realize the fact that they are at the same time the environment for nonhuman organisms. " $\mathrm{Li}$ ving things respond to what environs them, but in their responses they environ other things. 'Environ-' encourages the distin- 
ction between nature and culture ...; 'eco-' encourages seeing both nature and culture as interconnected parts contained by the Earth and its ecology" (Wess, 2005). Nonetheless, "ecocrticism" is not unproblematic. Different voice is heard from Stephanie Sarver, who argues that the term "ecocriticism" is vague and perhaps misleading for if the term is directed to literary analysis of the relationship between humans and nature, it can be better labeled an environmental approach to literature or simply environmentalism. In Sarver's view, the term "ecocriticism" is more jargon-like than a descriptive term for it descrybes neither a philosophy nor an activity. She assumes that if she utters the word to a group of ecologists, they will be confused with what she is alluding to, and if she calls herself an environmentalist who studies literature then both academic and nonacademic audiences generally will understand what values inform her work. Another misleading aspect is that "ecocriticism" sounds like suggesting a new kind of critical theory while it is actually more a focus on environment than a theory. Ecocritics can apply theories of feminism, Marxism and psychoanalysis to do literary studies and reflect "not the science of ecology, but a broad-based environmentalist sensibility" (Sarver, 1994).

Not coincidentally, a group of Chinese scholars have unconsciously stepped into this argument. A comprehensive research institute, Research Center for Eco-Environmental Sciences, Chinese Academy of Sciences (RCEES) has been established since 1986. From the naming of the institute comes the term "eco-envrionmental", which is a combination of "ecology" and "environment" but it can also serve as the solution to the "ecocriticism" and "environmentalism" dispute in that "eco -environment" can be regarded as a reconciliation between "eco-" (nature-oriented) and "environ-" (culture-oriented). As for the applications of the two terms in this study, accepted fixed expressions or allocations have been applied in order not to cause any possible confusion.
Anti-anthropocentrism may sometimes go to the other extreme of being misanthropic. The following are two examples of misanthropy. Edward Abbey once asserts that he would rather kill a man than a snake, while Garret Hardin also claims that wilderness settings should be valued above individual human lives (Callicott, 1992). Anti-anthropocentrism does not mean anti-human. There is neither a preference for man nor a preference for nature. It points to a harmonized stance of treating man and nature equally. Ecocentrism, regarding the environment as just a setting for human events, is similar to anthropocentrism, both directing towards a certain hierarchy that privileges the human over the nonhuman.

Realizing "anthropocentrism" provides us with a comprehendsion of the deep root of the environmental problems. What we often confidently discuss "modifying the environment" implies man-centered logic as well, treating the natural world as if it existed only for human use. Humans, at most, are humble members of a larger community of living beings, not superior to any of the other creatures, embodying no right in destroying the biodiversity for their own good. Human benefit should never be the sole reason of a green environment, nor should it be the yardstick against which the necessity of environmental protection is put in force. The eco-environmental optimization should be a global optimization (Li et al., 2008; Lv et al., 2010; Chen et al., 2016). The development objective of all jurisdictions should not be partial optimization for human benefit or partial optimization for environment (Qin et al., 2007; Cai et al., 2009; Li and Huang, 2009; Li et al., 2010). To maintain the harmony of the large community of humans and nonhumans, it is important to stick to the concept of anti-anthropocentrism, to unsettle anthropocentric norms. To harmonize with the natural world, we should get rid of the anthroponormative thinking. Human world and natural world are not binaries. They are an organic whole, highly interdependdent and actively interact with each other.

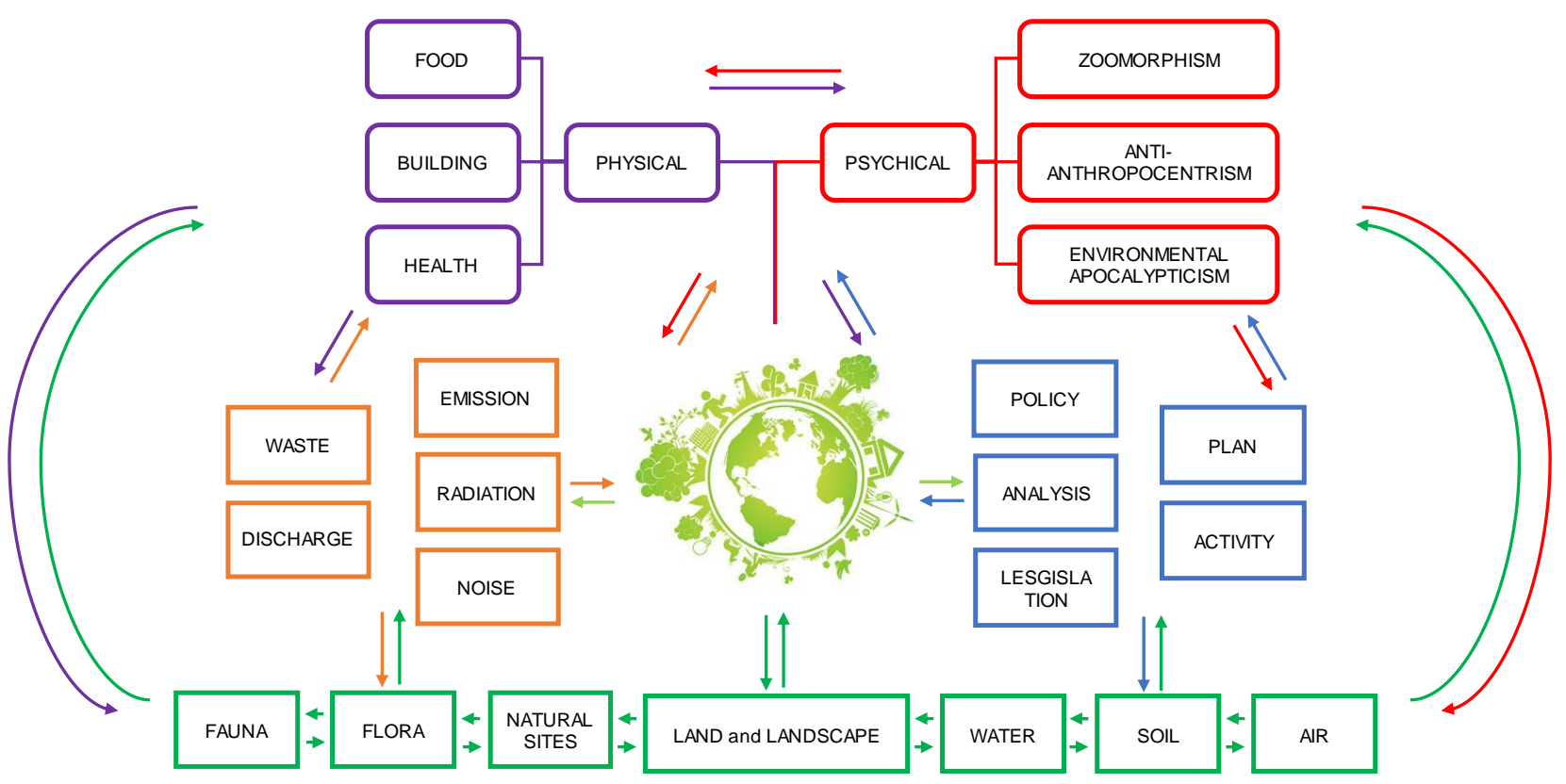

Figure 2. Environmental information systems. 


\section{Discussion}

\subsection{Environmental Information System}

Environmental information plays an important role in policy-making throughout the world. Both governments and the public pay more and more attention to environmental information and its availability (Günther, 1997). Environmental information has a broad definition. Till now, the most accepted definition of environmental information is from the Freedom of Access to Information on the Environment Regulations of 2005 (Department of Information, 2005). According to the definetion in LN 116 OF 2005, the environmental information contains information in written, visual, aural, electronic or any other material forms. Specifically, the information is mainly in six areas, including the state of the elements of the environment, factors, measures, reports, analyses, and the state of human health and safety (Department of Information, 2005).

Through the foregoing sections, it is essential to fully understand the interactions between human and nature. Along with the advancement of the society, human activities have a growing influence on the environment. Meanwhile, the environment has great impacts on humans both physically and psychically. People's spirit and consciousness will affect and guide their actual behaviors. Taking all of these into consideration, environmental information becomes a comprehensive system, which includes various components and complicated interacttions among them.

In order to better reflect the systematicness and complexity, the environmental information system has been developed accordingly, as shown in Figure 2. In this system, the state of the elements of the environment (e.g. water, air and soil) and their interactions are considered as the basic layer. There are two different categories of human activities in the second layer. The activities that destroying environment are classified into the negative activities, such as emission, waste, noise and so on. On the contrary, the activities that protect or repair environment are classified into the positive activities, including environmenttal analysis, policy and so on. The top layer in the system is the physical and psychical state of humans. The physical state of humans includes health, food and so on, which has been quite thoroughly discussed in the previous studies. The psychical state of humans refers to the effects of the environment on human's spirit and consciousness, which is mostly neglected in the previous studies.

Data and information availability is another challenge faced by all. Firstly, most of the previous studies focused on the objective environmental information and ignored the subjective consciousness and its feedback to the objective facts. One important reason is that it is extremely difficult to obtain and analyze subjective consciousness information through tradetional environmental engineering research. In addition, the objective environmental information is also hard to be found before environmental monitoring equipment is invented and applied.

Ecocriticism is the bridge and ties between engineering study and social sciences. It can also provide much more detailed objective environmental information of different periods. To illustrate the necessity and feasibility of the environmental information in modern fiction, we searched the scientific environmental information related to the literary works in this study,

Table 1. Environmental Information of UK During 1950-1960

\begin{tabular}{|c|c|c|}
\hline Number & Title & Source \\
\hline 1 & Live Births by Age of Mother, Great Britain, 1950 to 2015 & (Office of National Statistics, 2017) \\
\hline 2 & Numbers of UK Women Born in 1950's, 1940's and 1930's & (Office of National Statistics, 2016a) \\
\hline 3 & $\begin{array}{l}\text { Age specific mortality rates where the underlying cause of death was asthma, England } \\
\text { and Wales, 1960, } 1966 \text { and } 2014\end{array}$ & (Office of National Statistics, 2016b) \\
\hline 4 & $\begin{array}{l}\text { The Past, Current and Future Radiological Impact of the Sellafield Marine Discharges } \\
\text { on the People Living in the Coastal Communities Surrounding the Irish Sea }\end{array}$ & (Environmental Agecny, 2001) \\
\hline 5 & $\begin{array}{l}\text { JSA claimants by sex, month and year of birth between } 1950 \text { and } 1965 \text { in GB: May } \\
2000 \text { to May } 2012\end{array}$ & $\begin{array}{l}\text { (Department for Work and Pensions, } \\
\text { 2014) }\end{array}$ \\
\hline 6 & Historic National Food Survey reports from 1940 to 1984 & $\begin{array}{l}\text { (Department for Environment, Food } \\
\text { \& Rural Affairs, 2016) }\end{array}$ \\
\hline 7 & Visibility trends in the UK $1950-1997$ & (Doyle and Dorling, 2002) \\
\hline 8 & The world food problem: $1950-1980$ & (Grigg, 1985) \\
\hline 9 & $\begin{array}{l}\text { The growth of energy consumption and prices in the USA, FRG, France and the UK } \\
1950-1980\end{array}$ & (Doblin, 1982) \\
\hline 10 & $\begin{array}{l}\text { UK natural gas system integration in the making, 1960-2010: Complexity, transitional } \\
\text { uncertainties and uncertain transitions }\end{array}$ & (Arapostathis et al., 2014) \\
\hline 11 & $\begin{array}{l}\text { Building resilience to overheating into } 1960 \text { 's UK hospital buildings within the } \\
\text { constraint of the national carbon reduction target: Adaptive strategies }\end{array}$ & (Short et al., 2012) \\
\hline 12 & UK and western European late-age mortality: trends in cause-specific death rates, $1960-1990$ & (Warnes, 1999) \\
\hline 13 & The disappearance of leaf litter and its contribution to production in the River Thames & (Mathews and Kowalczewski, 1969) \\
\hline 14 & Flood risk management in the Thames Estuary looking ahead 100 years & (Lavery and Donovan, 2005) \\
\hline 15 & The growth and mortality of four species of fish in the River Thames at Reading. & (Williams, 1967) \\
\hline 16 & The Thames Embankment and the disciplining of nature in modernity. & (Oliver, 2000) \\
\hline 17 & The field of psychiatric contention in the UK, $1960-2000$ & (Crossley, 2006) \\
\hline
\end{tabular}


as shown in Table 1.

Limited statistic data and papers have been found by setting the key words as the historical background of the case studies (e.g. 1950 - 1960). From the Office of National Statistic and UK government website, public can obtain the environmental information about birth, mortality, food, and radiological impact of the Sellafield marine discharges. The scientific papers that contain the environmental information of UK are also rarely founded. From Table 1, we can see that most of the studies are focused on food, health, energy and other objective elements. Specially, there are some studies about River Thames, which is one of the most important environmental elements in Offshore. The studies mainly focused on flood, waste, fishes, and constructions. The scientific environmental information of UK during 1950 to 1960 is limited in both species and amount.

Table 2 shows the environmental information type that contained by scientific studies and modern fictions in this study. The state of the elements of the environment, that is, water, energy, animal, air, and soil, are involved in both scientific study and ecocriticism. It is worthwhile to mention that the information about the element of energy in the scientific study apparently exceed other elements'. In this study, a large quantity of the environmental information regarding the element of water, which including river, sea, water quality, water utilization, tide, and food, comes from the ecocriticism due to the seaside and riverside backgrounds. In terms of negative human activities, the elements of emission, waste, and radiation are studied in the science environmental engineering study while only the first two elements are discussed in ecocriticism. The biggest differrence between the scientific study and ecocriticism is their different focuses on either physical or psychical state of humans. More specifically, the scientific study focuses on, for example, the birth, health, food, and building from the physical state, especially on the health study. A specific study on the health, birth, job, food, building, safety, and transportation from the physical state is conducted on a basis of the selected cases. It is seen from the Table that no psychical state of human is explored in the scientific study but certain crucial environmental ideologies are actually incorporated in modern fictions, which can greatly contribute to the study of the environment. Overall, it is concluded that an interdisciplinary study of science and literature is complementary and capable of covering all environmental information.

\subsection{Future Work}

In Penelope Fitzgerald's works, the narratives of the natural environment have been used as a descriptive tool for readers to envisage a different concept of environmental consciousness, rich in its connotations. Through Fitzgerald's stories of nature reacting to ignorance and intrusion, as well as the human's response to the damage modernization brings, we come to realize the urgent need for environmental protection and ecological balance. "Human progress has created ecological regression and where the quest for advancement is won at the cost of nature, no advantages can be gained for anyone involved. We should be clear that the protection of nature should start
Table 2. Comparison of Environmental Information from Different Sources

\begin{tabular}{|c|c|c|c|c|}
\hline \multicolumn{2}{|c|}{$\begin{array}{l}\text { Environmental } \\
\text { information }\end{array}$} & \multicolumn{2}{|r|}{$\begin{array}{l}\text { Ecocritial } \\
\text { information }\end{array}$} & $\begin{array}{c}\text { Scientific } \\
\text { information }\end{array}$ \\
\hline \multirow{5}{*}{$\begin{array}{l}\text { Elements of } \\
\text { the } \\
\text { environment }\end{array}$} & Water & $\sqrt{ }$ & $(\mathrm{a})(\mathrm{b})(\mathrm{e})(\mathrm{l})$ & $* \quad(13)(14)$ \\
\hline & Energy & $\sqrt{ }$ & (e) & $* \quad(9)(10)$ \\
\hline & Animal & $\sqrt{ }$ & (f)(i) & * (15) \\
\hline & Air & $\sqrt{ }$ & (e) & \\
\hline & Soil & $\sqrt{ }$ & (d) & \\
\hline \multirow{3}{*}{$\begin{array}{l}\text { Negative } \\
\text { human } \\
\text { activities }\end{array}$} & Emission & $\sqrt{ }$ & (e) & * (7) \\
\hline & Waste & $\sqrt{ }$ & $(\mathrm{b})(\mathrm{c})(\mathrm{d})$ & * (13) \\
\hline & Radiation & & & * (4) \\
\hline \multirow{3}{*}{$\begin{array}{l}\text { Positive } \\
\text { human } \\
\text { activities }\end{array}$} & Analysis & & & \\
\hline & Policy & & & \\
\hline & Legislation & & & \\
\hline \multirow[t]{7}{*}{$\begin{array}{l}\text { Physical } \\
\text { state }\end{array}$} & Health & & & $\begin{array}{ll}* \quad(3)(4)(11) \\
& (12)(17)\end{array}$ \\
\hline & Birth & & & * (1)(2) \\
\hline & Job & & & * (5) \\
\hline & Food & & & * (6)(8) \\
\hline & Building & $\sqrt{ }$ & (a)(e) & * (11)(16) \\
\hline & Safety & $\sqrt{ }$ & $(\mathrm{g})(\mathrm{h})(\mathrm{j})(\mathrm{l})$ & * (7) \\
\hline & Transportation & $\sqrt{ }$ & $(\mathrm{h})(\mathrm{j})$ & \\
\hline \multirow{3}{*}{$\begin{array}{l}\text { Psychical } \\
\text { state }\end{array}$} & Zoomorphism & $\sqrt{ }$ & $(\mathrm{f})(\mathrm{j})$ & \\
\hline & $\begin{array}{l}\text { Anti- } \\
\text { anthropocentrism }\end{array}$ & $\sqrt{ }$ & (1) & \\
\hline & $\begin{array}{l}\text { Environmental } \\
\text { apocalypiticism }\end{array}$ & $\sqrt{ }$ & $\begin{array}{l}(\mathrm{g})(\mathrm{h})(\mathrm{i}) \\
(\mathrm{j})(\mathrm{k})\end{array}$ & \\
\hline
\end{tabular}

Note: " $"$ " and "*" denote "focus of attention".

with a renewed relationship with it, a tie that should exemplify unfailing knowledge and respect for nature" (Hope SubanpanYu, 2009). Hutchings also affirms that Human welfare and prosperity depend to a great extent upon nature's well-being and our ability to formulate ecologically sustainable practices (Hutchings, 2005). Thus, if the creation of literature is an important characteristic of the human species, it should be examined carefully and honestly to discover its influence upon human behavior and the natural environment-to determine what role, if any, it plays in the welfare and survival of mankind and what insight it offers into human relationships with other species and with the world around us. Is it an activity which adapts us better to the world or one which estranges us from it? From the unforgiving perspective of evolution and natural selection, does literature contribute more to our survival than it does to our extinction (Meeker, 1978)?

This study has limitations that should be addressed in future research. A wider range of the 1960s and modern writing can be included to make the interdisciplinary study of literature and environment more firmly-founded. Also, the methodology of the study is highly social sciences-oriented. With the active participation of science cooperators, the outlook is positive. As Stebbins appeals that science requires the dispassionate evidence of controlled experimentation (Stebbins, 1993), next steps should incorporate and investigate some data in the field of ecocriticism. Understanding the generality and obtaining the 
objectivity is important to success in the interdisciplinary research efforts.

As mentioned earlier, the efficacy of data-driven modelling may be dependent on the amount and quality of data available. The available dataset has a resolution of 96 samples per day (corresponding to sampling every 15 minutes) for most years. As an additional test to compare the two data-driven models, the resolution of the input dataset was reduced from 96 samples, first to 24 samples per day (sampling every hour), and then to 6 samples per day (sampling every 4 hours). Then, the entire analysis (i.e. calibrating and validating the nine recursive models, M01-M09) was repeated using the lower resolution datasets, at each of the four lags. In other words, for the initial case, mean daily DO was calculated using 96 samples for each day, which reduced to using 24 samples for the second case, and only 6 samples in the last case. This was done to compare the change in performance of both methods as the available data was reduced. Results from this component of the research can assist in determining an optimal data sampling scheme.

\section{Conclusions}

How do literary works narrate and depict environments? What significance it bears? In this study, the concept of ecocriticism has been applied to the discourses of environment in fictions, particularly in Penelope Fitzgerald's works. Ecocriticism expands the scope of the science environmental study because it examines and tries to understand human experience in its literary representations, not just in real life. Besides, some literary works or cultural documents can function as invaluable historical documents to follow and compare the changes of the environment.

Environmental awareness and zoomorphism have been examined through detailed examples in Offshore, The Bookshop and The Red-Haired Girl. This has been followed by studies of environmental apocalypticism based on certain alarming scenes as represented in Fitzgerald's works. Moreover, anti-anthropocentrism has been analyzed and emphasized according to the dissolution of dichotomy between man and nature. The core of Penelope Fitzgerald's environmental thoughts is public health environmentalism, which, according to Lawrence Buell, "whose geographic gaze was directed more at landscapes of urban and industrial transformation" (Buell, 2011).

Based on this research effort, discourses of the environment in some modern fiction have been conceptualized. With the conceptual overview, environmental problems and prospects are more closely and clearly examined. The perspective of this research sharpens the science environmentalists' views and awareness in the light of social sciences views on the environment, improving both sides' cultural sensitivity. The inclusion of environmental ethics is of great importance to the science environmentalist in that when they consider environmental issues they should treat human benefit and non-human world, both sides equal. The emphasis on interdisciplinary perspective when discussing environmental issues prepares scholars in an expanding field with a broader outlook.
Compared with the science environment engineering, approaching the issues of the environment from the literary perspective is subjective and sometimes emotional. The subjectivity, however, increases the sense of responsibility and makes good on our moral intuitions. And the combining of the two visions can more efficiently convert our concerns into effective action. The environmental study from ecocriticism provides the sciences with a shift from scientific pragmatism to moral idealism.

Buell posits at the outset of his study, The Environment Imagination: Thoreau, Nature Writing, and the Formation of American Culture, four criteria for works labeled "environmentally oriented": (1) "the nonhuman environment is present not merely as a framing device but as a presence that begins to suggest that human history is implicated in natural history"; (2) "the human interest is not understood to be the only legitimate interest"; (3) "human accountability to the environment is part of the text's ethical orientation"; and (4) "some sense of the environment as a process rather than as a constant or a given is at least implicit in the text" (Buell, 1995). This study is advanced through an ecocritical perspective of modern fiction, especially that of Penelope Fitzgerald's works. It aims to rouse the social conscience that flows in her works. To some researchers, Fitzgerald's writing of the urban environment may seem impressionistic and suggestive, but it can serve as the foundation for environmentalists' capacity to reveal and to explore. The function and significance of this criticism lies in the social construction of the environmental perception. A positive outcome of ecocriticism is that it offers an insight and suggests an open and promising future for interdisciplinary research that can help us understand the world better, rouse our environmental ethics and think our way toward solutions to environmental problems, from a different and effective perspective.

Acknowledgements. The authors are grateful to the anonymous reviewers for their insightful comments and suggestions which contributed much to improving the manuscript. Thanks also go to the editors for all their effort in constructively feeding back on early versions of this article.

\section{References}

An, C., Yang, S., Huang, G., Zhao, S., Zhang, P., and Yao, Y. (2016). Removal of sulfonated humic acid from aqueous phase by modified coal fly ash waste: Equilibrium and kinetic adsorption studies. Fuel, 165, 264-271. https://doi.org/10.1016/j.fuel.2015.10.069

Arapostathis, S., Pearson, P.J., and Foxon, T.J. (2014). UK natural gas system integration in the making, 1960-2010: Complexity, transitional uncertainties and uncertain transitions. Environ. Innov. Soc. Trans., 11, 87-102. https://doi.org/10.1016/j.eist.2014.01.004

Buell, L. (1995). The Environmental Imagination: Thoreau, Nature Writing, and The Formation of American Culture, Cambridge: Belknap Press.

Buell, Lawrence. (2011). Ecocriticism: some emerging trends. Qui Parle, 19(2), 87-115. https://doi.org/10.5250/quiparle.19.2.0087

Cai, Y.P., Huang, G.H., Yang, Z.F., Lin, Q.G., and Tan, Q. (2009). Community-scale renewable energy systems planning under uncertainty-an interval chance-constrained programming approach. Renew. Sust. Energy. Rev., 13(4), 721-735. https://doi.org/10.1016/j. rser.2008.01.008 
Callicott, J.B. (1992). Animal liberation: a triangular affair. Environ. Ethics, 37-69.

Chen, F., Huang, G.H., Fan, Y.R., and Liao, R.F. (2016). A nonlinear fractional programming approach for environmental-economic power dispatch. Int. J. Elec. Power., 78, 463-469. https://doi.org/10.10 16/j.ijepes.2015.11.118

Crossley, N. (2006). The field of psychiatric contention in the UK, 1960-2000. Soc. Sci. Med., 62(3), 552-563. https://doi.org/10. 1016/j.socscimed.2005.06.016

Department for Environment, Food \& Rural Affairs. (2016). Family food historic reports. https://www.gov.uk/government/statistics/ family-food-historic-reports

Department for Work and Pensions. (2014). JSA claimants by sex, month and year of birth between 1950 and 1965 in GB: May 2000 to May 2012. https://www.gov.uk/government/publications/jsaclaimants-by-sex-month-and-year-of-birth-between-1950-and-196 5-in-gb-may-2000-to-may-2012

Department of Information. (2005). Environment Protection Act. htt$\mathrm{p}: / / w w w . j u s t i c e s e r v i c e s . g o v . m t / D o w n l o a d D o c u m e n t . a s p x ? a p p=l p$ \&itemid $=16953 \& \mathrm{l}=1$

Doblin, C.P. (1982). The Growth of Energy Consumption and Prices in the USA, FRG, France, and the UK, 1950-1980, International Institute for Applied Systems Analysis, Luxemberg, Austria.

Doyle, M. and Dorling, S. (2002). Visibility trends in the UK 19501997. Atmos Environ, 36(19), 3161-3172.

Estok, S.C. (2011). Ecocriticism and Shakespeare: Reading Ecophobia, Palgrave Macmillan, New York. https://doi.org/10.1057/978023 0118744

Environment Agency. (2001). The past, current and future radiological impact of the sellafield marine discharges on the people living in the coastal communities. https://www.gov.uk/government/publications /the-past-current-and-future-radiological-impact-of-the-sellafieldmarine-discharges-on-the-people-living-in-the-coastalcommunities

Ewards, B. (2009). Rough Guide to Sustainability (3rd ed.), RIBAPublishing.

Fan, Y.R., Huang, W.W., Huang, G.H., Huang, K., Li, Y.P., and Kong, X.M. (2015). Bivariate hydrologic risk analysis based on a coupled entropy-copula method for the Xiangxi River in the Three Gorges Reservoir area, China. Theor. Appl. Climatol., 125(1-2), 381-397. https://doi.org/10.1007/s00704-015-1505-z

Fitzgerald, P. (1998). The Beginning of Spring, Mariner Books, London.

Fitzgerald, P. (2001). The Means of Escape, Flamingo, London.

Fitzgerald, P. (2006). The Bookshop, Harper Perennial, London.

Fitzgerald, P. (2009). Offshore, Fourth Estate, London.

Glotfelty, C. (1996). Introduction: Literary Studies in an Age of Environmental Crisis. The Ecocriticism Reader: Landmarks in Literary Ecology, University of Georgia Press, Athens.

Grigg, D. (1985). The World Food Problem 1950-1980, Oxford: Basil Blackwell.

Günther, O. (1997). Environmental information systems. ACM SIGMOD Rec., 26(1), 3-4. https://doi.org/10.1145/248603.248604

Huang, G.H. (1998). A hybrid inexact-stochastic water management model. Eur. J. Oper. Res., 107(1), 137-158. https://doi.org/10.1016/ S0377-2217(97)00144-6

Huang, G.H., and Loucks, D.P. (2000). An inexact two-stage stochastic programming model for water resources management under uncertainty. Civ. Eng. Environ. Syst., 17(2), 95-118. https://doi.org/10.10 80/02630250008970277

Huang, G.H., Huang, Y.F., Wang, G.Q., and Xiao, H.N. (2006). Development of a forecasting system for supporting remediation design and process control based on NAPL-biodegradation simulation and stepwise-cluster analysis. Water Resour. Res., 42(6). https: //doi.org/10.1029/2005WR004006

Hubbard, D. (2009). The Failure of Risk Management: Why It's
Broken and How to Fix It. John Wiley \& Sons.

Hutchings, K. (2005). Don't call me a tree hugger!: sticks, stones, and stereotypes in ecocriticism. Interdiscip. Literary Stud., 7(1), 5-26.

Huxley, A. (1963). Literature and Science, Chatto \& Windus Ltd, London.

Khan, U. T., and Valeo, C. (2016). Short-term peak flow rate prediction and flood risk assessment using fuzzy linear regression. J. Environ. Inf., 28(2), 71-89. https://doi.org/10.3808/jei.201600345

Kermode, F. (1979). Booker Books, London Review of Books. pp.12-13.

Lavery, S., and Donovan, B. (2005). Flood risk management in the Thames Estuary looking ahead 100 years. Philos. Trans. R. Soc. Lond. A: Math., Phys. Eng. Sci., 363(1831), 1455-1474. https://doi. org/10.1098/rsta.2005.1579

Lee, Hermione. (2013). Penelope Fitzgerald: ALife, Chatto \& Windus, London.

Li, Y.P., and Huang, G.H. (2009). Fuzzy-stochastic-based violation analysis method for planning water resources management systems with uncertain information. Inf. Sci., 179(24), 4261-4276. https:// doi.org/10.1016/j.ins.2009.09.001

Li, Y.P., Huang, G.H., Huang, Y.F., and Zhou, H.D. (2009). A multi-stage fuzzy-stochastic programming model for supporting sustain-nable water-resources allocation and management. Environ. Model. Software, 24(7), 786-797. https://doi.org/10.1016/j.envsoft.2008.11.008

Li, Y.P., Huang, G.H., Nie, S.L., and Liu, L. (2008). Inexact multistage stochastic integer programming for water resources management under uncertainty. J. Environ. Manage., 88(1). 93-107. https://doi. org/10.1016/j.jenvman.2007.01.056

Li, Y.P., Huang, G.H., Yang, Z.F., and Nie, S.L. (2008). IFMP: intervalfuzzy multistage programming for water resources management under uncertainty. Resour. Conserv. Recycling, 52(5), 800-812. https://doi.org/10.1016/j.resconrec.2007.11.007

Li, Y.P., Huang, G.H., and Nie, S.L. (2010). Planning water resources management systems using a fuzzy-boundary interval-stochastic programming method. Adv. Water Resour., 33(9), 1105-1117. https://doi.org/10.1016/j.advwatres.2010.06.015

Love, G.A. and Love, R.M. (1971). Ecological Crisis: Readings for Survival, Harcourt Brace Jovanovich, Inc.

Love, G.A. (1999). Ecocriticism and science: toward consilience? New Literary Hist., 30(3), 561-576. https://doi.org/10.1353/nlh.199 9.0039

Lv, Y., Huang, G.H., Li, Y.P., Yang, Z.F., Liu, Y., and Cheng, G.H. (2010). Planning regional water resources system using an interval fuzzy bi-level programming method. J. Environ. Inf., 16(2), 43-56. https://doi.org/10.3808/jei.201000177

Marshall, I. (2005). New Connections in Ecocriticism. Interdiscip. Literary Stud., 7(1), 1-4.

Martín-Fernández, L., Ruiz, D. P., Torija, A. J., and Míguez, J. (2016). A Bayesian method for model selection in environmental noise prediction. J. Environ. Inf., 27(1), 31-42. https://doi.org/10.3808/ jei.201500295

Mathews, C.P., and Kowalczewski, A. (1969). The disappearance of leaf litter and its contribution to production in the River Thames. J. Ecol., 57(2), 543-552. https://doi.org/10.2307/2258398

Meeker, J.W. (1978). Fields of danger and the wilderness of wisdom. The North American Review 263(1), 69-71.

Meeker, J.W. (1997). The Comedy of Survival: Literary Ecology and a Play Ethic (3 edition), University of Arizona Press, Tucson.

Nie, S., Huang, C.Z., Huang, G.H., Li, Y.P., Chen, J.P., Fan, Y.R., and Cheng, G.H. (2016). Planning renewable energy in electric power system for sustainable development under uncertainty - a case study of Beijing. Appl. Energy, 162, 772-786. https://doi.org/10.1016/j.ap energy.2015.10.158

Office for National Statistics. (2017). Live births by age of mother, Great Britain, 1950 to 2015. https://www.ons.gov.uk/peoplepopula tionandcommunity/birthsdeathsandmarriages/livebirths/adhocs/00 7063livebirthsbyageofmothergreatbritain1950to2015 
Office for National Statistics. (2016a). Numbers of UK women born in 1950's, 1940's and 1930's. https://www.ons.gov.uk/aboutus/ transparencyandgovernance/freedomofinformationfoi/numbersofu kwomenbornin1950s1940sand1930s

Office for National Statistics. (2016b). Age specific mortality rates where the underlying cause of death was asthma, England and Wales, 1960, 1966 and 2014. https://www.ons.gov.uk/peoplepopulation andcommunity/healthandsocialcare/causesofdeath/adhocs/005593a gespecificmortalityrateswheretheunderlyingcauseofdeathwasasthm aenglandandwales 19601966and2014

Oliver, S. (2000). The Thames embankment and the disciplining of nature in modernity. Geogr. J., 166(3), 227-238. https://doi.org/10. 1111/j.1475-4959.2000.tb00022.x

Phillips, D. (2003). The Truth of Ecology: Nature, Culture and Literature in America, Oxford University Press. https://doi.org/10.1093/ acprof:oso/9780195137699.001.0001

Qin, X.S., Huang, G.H., Zeng, G.M., Chakma, A., and Huang, Y.F. (2007). An interval-parameter fuzzy nonlinear optimization model for stream water quality management under uncertainty. Eur. J. Oper. Res., 180(3), 1331-1357. https://doi.org/10.1016/j.ejor.2006.03.053

Sabanpan-Yu H. (2009). Nature as persuasion: ecology in Gremer Chan Reyes's short fiction. Philipp. Q. Cult. Soc., 37(2/3), 159-172.

Sarver, S. (1994). What is ecocriticism? The association for the study of literature and the environment.

Short, C.A., Lomas, K.J., Giridharan, R., and Fair, A.J. (2012). Building resilience to overheating into 1960's UK hospital buildings within the constraint of the national carbon reduction target: Adaptive strategies. Build. Environ., 55, 73-95. https://doi.org/10. 1016/j.buildenv.2012.02.031

Simmons, N.C. and Scigaj, L.M. (1996). Review. J Engl. German. Phiology, 95(4), 577-580.

Stebbins, S. (1993). Anthropomorphism. Philos. Stud. Int. J. Philos. Anal. Tradit., 69(2-3), 113-122. https://doi.org/10.1007/BF00990077

Warnes, A.M. (1999). UK and western European late-age mortality: Trends in cause-specific death rates, 1960-1990. Health place, 5(1), 111-118. https://doi.org/10.1016/S1353-8292(98)00044-6

Williams, W.P. (1967). The growth and mortality of four species of fish in the River Thames at Reading. J. Anim. Ecol., 695-720. https://doi. org/10.2307/2821

Wess, Robert. (2005). Terministic screens and ecological foundations: a burkean perspective on Yamashita's "Through the Arc of the Rain Forest". Interdiscip. Literary Stud., 7(1), 104-115.

Wolfe, P. (2004). Understanding Penelope Fitzgerald, University of South Carolina Press, Columbia.

Woo, J. H., An, S. M., Hong, K., Kim, J. J., Lim, S. B., Kim, H. S., and Eum, J. H. (2016). Integration of CFD-Based virtual sensors to a ubiquitous sensor network to support micro-scale air quality management. J. Environ. Inf., 27(2), 85-97.

Zeng, X.T., Li, Y.P., Huang, G.H., and Liu, J. (2015). Modeling water trading under uncertainty for supporting water resources management in an arid region. J. Water Resour. Plann. Manage., 142(2). ht tps://doi.org/10.1061/(ASCE)WR.1943-5452.0000593. 